\title{
Protecting Rights in the Policy Process: Integrating Legal Proportionality and Policy Analysis
}

Mordechai Kremnitzer and Raanan Sulitzeanu-Kenan

\section{OpenEdition}

Electronic version

URL: https://journals.openedition.org/irpp/1974

DOI: 10.4000/irpp.1974

ISSN: 2706-6274

Publisher

International Public Policy Association

Printed version

Date of publication: 15 March 2021

ISSN: 2679-3873

Electronic reference

Mordechai Kremnitzer and Raanan Sulitzeanu-Kenan, "Protecting Rights in the Policy Process:

Integrating Legal Proportionality and Policy Analysis ", International Review of Public Policy [Online], 3:1 I 2021, Online since 15 March 2021, connection on 17 June 2021. URL: http://journals.openedition.org/ irpp/1974 ; DOI: https://doi.org/10.4000/irpp.1974

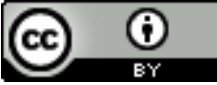




\section{Protecting Rights in the Policy Process: Integrating Legal Proportionality and Policy Analysis}

\section{Mordechai Kremnitzer \\ Professor Emeritus, Senior Fellow Center for Democratic Values and Institutions and Center for Security and Democracy, Israel}

\section{Raanan Sulitzeanu-Kenan}

Associate Professor, School of Public Policy, The Hebrew University of Jerusalem, Israel

\section{Abstract}

This paper provides an integrative analysis of legal proportionality and policy analysis, and identifies the inherent potential of integrating the proportionality principle in policy analysis for enhancing the protection of rights in the policy process. Our analysis entails three key recommendations: (1) Mandating the inclusion of a rights-impact criterion in policy analysis in order to increase the likelihood that the three proportionality tests will be addressed; (2) The professional norm of considering several distinct alternatives serves the normative requirement of the necessity test and facilitates the mitigation of rights restrictions through the comparison and modification of the alternatives; (3) Requiring policymakers to present the factual basis for the undesirable phenomenon in the course of judicial review of the policy goal. Such integration of policy analysis and proportionality can streamline the consideration of fundamental rights in the policy-making process and consequently increase their protection. Adopting these practical measures may substantially assist courts in identifying ways to implement judicial review, while respecting the discretion of policymakers. Finally, these proposed practices are expected to fine-tune the incentive structure of policy-makers for conducting quality policy analysis while protecting human and civil rights.

\section{Keywords}

policy analysis, civil rights, proportionality 


\section{Introduction}

Policy analysts often face conflicts between the need to promote desirable policies and the apparent need to apply harmful measures in doing so. One such type of conspicuous case has come to light in recent years as governments in the US and Europe have faced tides of illegal immigrants and refugees. Take, for example, the US government's practice of separating illegal immigrants from their children. In trying to stop the flow of migrants illegally crossing the border from Mexico to the US, the US administration has begun separating children from their families as a means of deterring future potential immigrants (Hirschfeld Davis \& Shear, 2018; Scherer \& Dawsey, 2018). While the purpose of the policy (enforcing immigration policies) may be legitimate, its implementation entails severe infringements of human rights. These means may be scrutinized from the perspective of policy analysis and the policy-making procedure: Was the immigration problem properly specified and defined? Were other alternatives evaluated and weighed against one another, taking into account their deterrent effect? A jurist may, on the other hand, examine the constitutionality of the means chosen and consider whether the infringements involved are proportional to the policy objective of deterrence. However, it is worth considering that these two realms are not as separate as one might think.

This article provides an integrative analysis of the relationship between legal proportionality and policy analysis. We propose that it is necessary to break through the current divide between the two fields and to forego the view that proportionality is handled exclusively by courts and policy analysis by policy analysts. Instead, policy-making should and can be conducted in a way that facilitates the proportionality doctrine, while the latter is adapted to the unique goals and practices of policy analysis. Such integration of proportionality in policy analysis can streamline the consideration of fundamental rights in the policy-making process and consequently increase their protection. We further suggest that the proposed integration of proportionality in policy analysis may complement the limitations of courts in performing judicial review of policy, by offering courts procedural criteria, in addition to the often contested substantive criteria.

The analysis presented in this paper complements existing studies of 'constitutional dialogues' (Fisher, 1988, Hogg \& Bushell 1997, Stone-Sweet, 2000, Hiebert, 2006), which describe institutional processes that stem from potential and actual judicial rulings regarding the constitutionality of legislation (Stone-Sweet \& Mathews, 2019, p. 128) and their political implications (ibid, p. 135). Such studies take a descriptive approach and focus on the institutional dynamics across different systems. The current study, on the other hand, takes a normative approach to identify specific ways of applying the proportionality principle in policy analysis, and the normative implications of these processes for judicial review. We draw on existing methods of policy analysis and legal principles and follow a normative approach in the sense that we aim to enhance rights protection in the policy process.

The implications of this paper delineate clearer and more effective roles for both the legislative and executive branches of government in the protection of rights in general, and with respect to proportionality analysis in particular. These analyses and consequent proposals are applicable both in systems where constitutional courts are veto players (e.g., Germany), as well as those in which parliaments maintain the enforceability of a statute after a court has found it to have violated a constitutional right (e.g., Canada, UK and New Zealand) ${ }^{1}$.

\footnotetext{
1 - The aim of this paper is not to replace judicial review by integrating proportionality into the policy process, but to improve the protection of rights by integrating proportionality in the policy process, and to offer more concrete specifications for judicial review of policy. In parliamentary democracies where the final determination is made by parliament (dominated by the government), enhancing the role of policy analysis in protecting rights is expected to be even more important.
} 
The article begins with a brief presentation of the two domains: the first section outlines constitutional proportionality and the second section delineates policy analysis. Next, we review key differences between the practice of judges and that of policy analysts, with the aim of designing the stages of policy analysis in a manner that suits its unique characteristics. Drawing on these foundations, we propose broad guidelines for a normative model of policy analysis that accommodates the requirements of proportionality. Lastly, we consider and discuss the implications of this potential development in policy analysis for the practice of judicial review of public policy.

\section{Proportionality}

The proportionality framework is a prominent legal doctrine in many democratic societies for resolving conflicts that often arise between public objectives and individual constitutional rights that may be restricted by the policy (Alexy, 2010; Beatty, 2004; Kumm, 2007; Petersen, 2013; Stone Sweet \& Mathews, 2008). Using the proportionality framework, judges determine whether, and to what extent, individual rights can be restricted for the sake of promoting or protecting various public interests. In recent decades proportionality has become a central tenet of global constitutional law and a defining element in the protection of human rights (Beatty, 2004; Hurka, 2005; Jackson, 2004; Sulitzeanu-Kenan et al., 2016).

Proportionality analysis is a sequential set of legal decision-making stages: two preliminary stages and three integral stages of the process itself (Alexy, 2010; Kumm, 2007). The first preliminary stage - infringement of rights - involves an assessment of whether the policy in question entails a potential infringement of constitutionally protected rights. The second preliminary stage - goal-worthiness - examines the worthiness or legitimacy of the goal or interest that the policy seeks to promote. Unworthy reasons for limiting constitutional rights may include sectarian, sexist, homophobic, and racist preferences. More generally, this stage may facilitate an assessment of whether the infringement of the right is deliberate, or an incidental consequence of policy implementation (Kumm, 2007).

The first integral decision stage of proportionality analysis - suitability - examines whether the measures adopted to further a policy are rationally related to the stated policy objective - i.e., the worthy goal. In other words, suitability is a minimalistic standard of effectiveness, as it requires assessment of whether the policy measure sought is expected to promote the policy objective. The second integral decision stage - necessity or least restrictive means (LRM) - examines whether the policy measure entails the minimum violation of rights necessary. Thus, if an alternative means can attain the policy goal to the same or a similar degree with a lesser infringement of rights, the alternative means must be preferred. Finally, the third integral stage of proportionality analysis - balancing (or strict-sense balancing) - is implemented if the policy means satisfies the previous tests, and it assesses whether the benefits of the policy justify its costs in terms of rights infringement. In other words, it requires an appropriate relationship between the marginal utility gained by promoting the policy goal and the marginal harm to individual rights expected from implementing the policy.

The stages of proportionality analysis structure decision-makers' discretion and bolster a culture of justification (Cohen-Eliya \& Porat, 2013) - the notion that government actions must be factually and morally justified in order to be legitimate in general, and in adjudicating rights considerations in particular. However, the existing literature provides little guidance as to the exact methods of doing so, thus leading to a practice that separates policy analysis from the 'in-house' rights review (Stone-Sweet \& Mathews, 2019, p. 135). This separation is further 
exacerbated by the fact that the former process is conducted by policy analysts while the latter is performed by legal advisors. We argue that sufficiently detailed methods of rights consideration within policy analysis is lacking, and that this lacuna perpetuates the perspective of rights considerations as peripheral to policy analysis and arguably limits the potential for identifying policy alternatives that are less restrictive of rights. This state of affairs may often result in an exercise in rationalisation rather than reasoning. Legal advisors may offer ex-post justification for almost any decision, even one that was not arrived at through a process of ex-ante analysis and consideration. Furthermore, a better understanding of how rights considerations can be implemented in policy analysis offers better guidance to the conduct of judicial review of policy. Hence we propose a model in which the question of justification - in light of proportionality analysis - is integrated within the process of policy analysis rather than after the fact. Within such a model, the role assumed by the court in judicial review of a policy is to consider the substantive policy, but also the quality of policy analysis, thus providing clearer and more practical guidance to policy analysts.

\section{Proportionality and Policy Analysis}

Proportionality provides a structured evaluation of whether a particular policy can be justified on the basis of public purposes that are appropriate in a liberal democracy (Kumm, 2010). This central characteristic of proportionality stems from the underlying notion that infringement of rights is permissible only if a persuasive justification can be provided. The proportionality tests seek, on the one hand, to identify and specify this justification and, on the other hand, to locate possible inferential failures in this justification, which may lead to the infringement of rights. Such failures may relate to the precise definition and delineation of the policy goal, in an empirically grounded fashion, or to a comparative examination of alternatives and the nature of the effective evaluations of these alternatives. Thus, proportionality includes basic elements of policy evaluation (Kumm, 2010, p. 150).

\section{Policy analysis}

Policy analysis is a complex, multistage process whose full description is beyond the scope of this article. This section will present a concise overview of appropriate policy analysis so as to facilitate the development of the discussion below regarding the relationship between policy analysis and the characteristics of the proportionality doctrine, both during the formulation of policy and in the course of judicial review.

A policy-making process is generally motivated by the identification of some undesirable phenomenon (Dery, 2000). Such a phenomenon is defined as some harm to public welfare in a broad sense, whether material or abstract. The harm may reflect a failure to realize potential or a missed opportunity to improve social welfare, such as failing to use solar radiation to produce energy in circumstances where solar radiation and available technology provide the conditions for doing so. Establishing that an undesirable phenomenon exists requires a thorough study of the quantitative and qualitative aspects of the phenomenon and its various dimensions (Bardach \& Patashnik, 2019; Weimer \& Vining, 2010). ${ }^{2}$ One example of an undesirable phenomenon is road congestion. A first step in addressing such a phenomenon is to examine its implications, both direct and indirect. For example, in addition to causing traffic delays, road congestion impedes economic productivity due to the loss of working hours, and increases

2 - We acknowledge that a policy problem is the product of an interaction between reality and perception and that what is deemed undesirable may be a matter of political conflict. However, we address policy problems perceived as such within a given society or epistemic community (Haas, 1992). 
exposure to air pollution and psychological stress, which entail adverse health consequences. Establishing this factual basis makes it possible to assess, primarily, that the undesirable phenomenon is real. Widespread unfounded misconceptions regarding various undesirable phenomena may sometimes stem from moral panic (Cohen, 2011; Goode \& Ben-Yehuda, 2009), often exacerbated by disproportionate media coverage of particularly dramatic and alarming events. Such events attract excessive attention, while questions regarding their actual prevalence, likelihood of recurrence, or relative severity vis-à-vis other social problems, are often disregarded. For example, tremendous media attention paid to traffic accidents in Israel over the years has led to an inflated public perception that this social problem constitutes a 'national scourge'. Yet, based on comparative measures, the risk of death in a road accident in Israel is among the lowest in the world (World Health Organization, 2015; OECD, 2017). Therefore, a preliminary requirement of appropriate policy analysis is to ascertain the factual basis of the existence and scale of an alleged undesirable phenomenon. ${ }^{3}$

In this preliminary stage, it is also necessary to perform an initial assessment of whether the undesirable phenomenon can be addressed by non-governmental measures, either in order to avoid excessive government intervention in society and the economy, to mitigate negative externalities (Weimer \& Vining, 2010), or to prevent infringement of rights. As we elaborate below, establishing the factual evidence of the existence and magnitude of the undesirable phenomenon also serves the goal-worthiness test of proportionality analysis. This process can establish whether addressing the alleged undesirable phenomenon indeed constitutes a real social need, rather than a populist initiative which may serve no clear purpose, or an alternative purpose that does not warrant the rights infringement (Roach, 2015).

Once the existence and scale of the undesirable phenomenon have been established, policy analysts must define the policy problem whose solution is expected to lead to a significant mitigation of the phenomenon (Bardach \& Patashnik, 2019; Dery, 1984; Reich, 1988). For example, when considering road congestion (the undesirable phenomenon), one may define the problem as one of insufficient infrastructure, thus leading to a particular set of policy alternatives, whereas problem definitions such as 'concentration of demand for road-use during peak hours' or 'inadequate use of public transit' would lead to different sets of policy alternatives. Establishing a causal link (even if uncertain) between the solution to, or mitigation of, a problem and an expected reduction in the scale of the undesirable phenomenon is an important consideration in choosing between alternative problem definitions. Moreover, such a process of problem definition may help in avoiding policy alternatives whose intended aims depart from the declared policy goal.

Defining the problem whose resolution can be expected to reduce the undesirable phenomenon efficiently is followed by formulating policy alternatives. A policy alternative is a course of action that is meant to reduce the undesirable phenomenon, and which coheres with the problem definition. For example, alternatives such as adding lanes and intersections may minimize the undesirable phenomenon when the problem is defined as insufficient infrastructure, whereas the alternative of staggered work hours for different sectors or geographic areas, in order to reduce peak traffic congestion (Henderson, 1981; Arnott et al., 2005), would accord with the definition of the problem as the concentration of the demand for road use.

3 - Note that establishing the existence and scale of the undesirable phenomenon involves a value judgment regarding how public welfare is measured (e.g., the value of human life, economic utility, or more abstract values such as equality). Therefore, these values should be stated explicitly. 
Appropriate policy analysis requires a conscious effort to identify several alternatives. The identification of alternatives relies on individual and group creative thinking and on learning from past experience - both domestic and international - through various consultation processes. The process of developing alternatives should be separated from the evaluation stage. These methods help policy analysts to overcome known obstacles to creativity, such as a fixation on standard solutions. Other obstacles to creativity are often related to a sense of urgency, whether justified or not, that accompanies policy-making. In order to minimize the harm that a sense of urgency could wreak on the quality of policy, it is sometimes desirable to develop alternatives aimed at 'buying time' and/or collecting information in order to provide a temporary response in the short-term, while creating conditions conducive to formulating optimal long-term policy (Hammond et al., 2015). ${ }^{4}$

The next stage of policy analysis includes a comparative evaluation of the alternatives and consequent selection of the optimal one. The alternatives are evaluated against a set of criteria or considerations. One central criterion is effectiveness - the degree to which an alternative is expected to mitigate the undesirable phenomenon. Additional criteria to be included should reflect various dimensions and consequences of the alternatives, such as cost, technological feasibility, externalities, and ramifications in terms of various values, including constitutional rights. After formulating a set of criteria, each criterion must be assigned a relative weight, as there is no reason to expect all the criteria to be of equal importance. Evaluation of alternatives must be based on the best evidence available to the policy analysts, including: scientific knowledge; past experience, whether domestic or international, in implementing similar policies; pilot programs; and any other reliable source. On the basis of this evidence, each alternative should be evaluated based on each criterion, in a process that is as clear, explicit and logical as possible. Subjective judgment should be used only where it is necessary (e.g., where direct evidence is lacking) - and be recorded as such. After the alternatives have been evaluated, the aggregate valuations of each alternative based on the weighted criteria are compared, and the alternative with the best overall score is selected.

This description of policy analysis is generic, in the sense that it can be implemented for a wide variety of policy problems, including those that have no impact on rights. This article aims primarily to point out how systematic policy analysis can be integrated with an explicit normative position regarding the protection of rights in policy formulation, as reflected in the principle of proportionality. The next section presents this integration.

\section{Integrating Proportionality and Policy Analysis}

The current professional separation between legal proportionality analysis and policy analysis hinders the implementation of proportionality by policy analysts and consequently diminishes their practical capacity to perform their duty of protecting rights, alongside legal advisors and courts. This predicament may lead policy analysts to assign insufficient weight to rights considerations in formulating policy recommendations and therefore to choose alternatives that unduly infringe civil rights. Moreover, this separation denies the courts clear guidelines for effective judicial review of the processes that have produced a particular policy.

In this section, we identify the potential relationships between policy analysis and legal proportionality, as applied by judges. At the outset, we consider the different characteristics of the two functions - adjudication and policy formulation - in order to identify ways of integrat-

4 - However, one should consider the unintended implications of temporary measures, inter-alia for the protection of rights (see: Motsenok et al., 2020). 
ing the proportionality tests within policy-making processes, and to delineate the appropriate expectations and demands of policy analysts that courts should apply in judicial review proceedings. We begin by pointing out some key distinctions between policy analysis and judicial review; next, we examine how an integrated analysis of these activities enables us to identify ways of facilitating the protection of rights in policy-making, and to illustrate how a better judicial understanding of well-conducted policy analysis can improve the judicial review of policy.

\section{Policy Analysis and Judicial Review}

Alec Stone Sweet argues that 'governing with judges also means governing like judges' (Stone Sweet, 2000, p. 204), suggesting that policy-making and legislative processes in countries that employ judicial review are affected by the way that courts evaluate policy. This argument rests on the prevalent assumption that, in order to satisfy legal requirements, a policy-making process should emulate ex ante the way in which courts conduct judicial review of policy. Furthermore, policy-makers rely on legal advisors, who naturally draw on what they are familiar with, i.e., how judges operate when they review policies. This naïve approach of emulating the court appears even more inexorable in the absence of a specified method for applying proportionality in the policy process.

Yet, despite the obvious need of policy analysts to consider the process of judicial review, this does not entail that they should mimic the methods used by judges. Our main argument is that, given the differences between policy analysis and judicial review, the concept of proportionality analysis should be implemented differently in the two domains in order to achieve more effective and streamlined protection of rights. The differences between the two processes include the order of the steps involved, the way the proportionality tests are implemented, and their relative importance. It should be noted that this article is not intended to outline a procedure that will guarantee success in passing judicial review (that would require a very different text), nor are we concerned here with ex-post justification of policies. Rather, we are attempting to integrate proportionality analysis within policy formulation throughout its stages.

The first difference between the two processes pertains to their goals. Policy analysis seeks solutions to public problems, whereas the goal of judicial review is to guarantee protected values and rights. Thus, while policy analysis may be carried out in contexts where there is no potential infringement of rights, as well as in circumstances where rights are involved, an infringement of a right is a primary and necessary condition for initiating proportionality analysis in judicial review. Relatedly, judicial review is dependent on a petition to the court and judicial proportionality decisions tend to be ad-hoc in nature (Beatty, 2004), focusing on the case in front of the court. Notably, only a small proportion of cases in which a right is violated are reviewed by courts, even under a liberal approach to standing rights (Felstiner et al., 1980). On the other hand, policy analysis must consider the question of proportionality of potential infringements of rights, even in the absence of any court proceeding, and well before any right is violated. These differences suggest that policy decisions affect the quality of life of millions far more pervasively than does judicial review of policy; thus democracy and civil rights are better served when proportionality is incorporated into the policy-making process than when it is merely a way of judging faulty policy after the fact. For these reasons, it is important to specify a method and guidelines for the evaluation of rights infringements in the policy process.

Second, given their divergent goals, judicial review and policy analysis also differ in their main criteria. In judicial review the dominant criterion is whether an infringement is justified, whereas in policy analysis it is whether the policy is effective and efficient in achieving 
its goals (Kumm, 2010, p. 150). For policy analysts, effectiveness is the initial motivation and the essence of the analysis. They are guided by the question of whether the chosen means can substantially mitigate the undesirable phenomenon. From a policy-analysis perspective, rights infringements are usually considered by-products and - where an obligation to uphold rights exists - as an undesirable by-product. In judicial review, infringement of a right and justification of the infringement take centre stage, while in questions of policy effectiveness, judges tend to defer to policymakers (see: Steiner et al. 2020, p. 568, who review the practice of apex courts in six countries). Thus, the objectives of policy analysis are broader and more diverse, even when the policy in question involves violations of rights. A full and precise specification of the undesirable phenomenon, followed by the most comprehensive identification possible of causes and problems, are the central, most important elements of policy analysis, yet they are not part of judicial proportionality analysis.

Third, proportionality analysis conducted by courts differs from policy analysis in its timing, and consequently in the scope and type of considerations involved. Policy analysts evaluate policy measures and their potential infringement of rights ex ante, while courts adjudicate these policy measures ex post. Furthermore, policy analysis is a continuous process and proportionality may be applied throughout the process, while judicial review applies proportionality in a limited timeframe. This distinction points to an important advantage of applying the proportionality principle in policy analysis, as it provides a process that can be adaptive to changing circumstances. For example, in 2014 the Israeli Supreme Court reviewed the government's policy regarding individuals, mostly African refugees and economic migrants, who entered the country illegally. This policy was intended to discourage future attempts at illegal immigration into the country by restricting the rights of those who managed to enter the country. However, since border control has significantly improved over time, the court suggested that the policy should be re-evaluated given these changing circumstances, which rendered the infringement of the immigrants' rights less justifiable (HCJ 7358/13).

When courts evaluate the proportionality of a particular policy measure, they do not consider its merit or efficiency (Kumm, 2010, p. 150), except in extreme cases of overt unreasonableness. In contrast, policy analysts are tasked with meticulously identifying and selecting the best policy measure, primarily in view of its effectiveness. This means that the considerations that play the most important role in policy analysis receive much less attention in judicial review. Courts consider effectiveness and efficiency against a minimum threshold of suitability for achieving the policy goal, as well as in the more comprehensive evaluation that is part of the final balancing test. Considerations of administrative expediency are not central to judicial review (e.g., see: Stacey, 2020, p. 250 [South Africa], Steiner, 2020, p. 350 [Israel]), whereas they may have great importance in the evaluation of policy alternatives. Policy consistency is addressed by courts mainly when inconsistency raises particular concerns, such as discrimination, or when it may indicate that the explicit policy goal masks another, covert purpose (Petersen, 2014a, 2014b). Legitimate priorities that might be critical to the policy-making agency, or even to the government, may not concern the court in its proportionality analysis.

Constitutional judicial review thus reflects a certain minimum threshold that a policy program must meet, while the expectations of policy analysis are different and much higher. Policy analysts are expected to attain the optimal aggregate outcome based on many derivative tasks and projects and are required to allocate resources efficiently among these tasks. The court, on the other hand, typically reviews a particular policy program with regard to one central criterion - the justification of an infringement of a right. This difference is analogous to maximizing an 
average score across a set of tasks (the administrative utility function), as opposed to requiring a passing grade on one particular task (the judicial requirement). Hence it would likely be detrimental to the quality of policy if analysts were to adopt the judicial implementation of the proportionality tests. For example, when the suitability of a policy measure for advancing a policy goal is evaluated in the context of judicial review, judges merely examine whether the measure is expected to advance the goal, leaving aside the level of effectiveness and the likelihood of the desired effect. In contrast, we expect policy analysts to identify the course of action that is most likely to promote the goal in the most effective way. In the same vein, in applying the necessity test, courts assess whether there is a similarly effective alternative that involves a lesser infringement of rights. They do not ask whether the chosen alternative is the most effective, as this is not their role. It is clearly the task of policy analysts to identify the best policy alternative, not merely one that passes the minimal constitutional requirement. We elaborate on these requirements in section 4.2 .

Policy analysis is also procedurally distinct from judicial review. The court evaluates one policy alternative only - the one already chosen and adopted by the legislature or executive branch. On the other hand, when policy analysts assess a particular plan, it is just one of several alternatives, as yet undecided upon. There is a difference between assessing a pre-selected alternative and one that is currently being considered. Policy analysts seek to specify the best and most suitable plan, given reasonably available resources. Therefore, they value the possibility of considering an alternative and of modifying, discarding or replacing it with another. An adequate method of policy analysis may involve dimensions stemming from its open, often unstructured nature, which cannot be part of an ex-post judicial review, as the judicial review begins after the policy-making process has ended and a particular policy plan has been chosen.

A further distinction between policy analysis and judicial review stems from the different capabilities, experiences and qualifications of the agents involved. Policy analysts have several advantages in terms of carrying out the function of selecting policy goals, as well as specifying and evaluating the appropriate means of achieving them. They are much more qualified for, and experienced in, gathering information and conducting various assessments - technical, economic or social - whether independently or by hiring experts. In contrast, legal interpretation is clearly the domain of the judicial branch, which is more experienced and has more training in formal value judgment than other branches (Roach, 2015, p. 410-411). The 'division of labour' between policy-making and judicial review must take these differences in qualifications into account. Inasmuch as courts rely on policy analysis conducted by the executive and legislative branches regarding the first two tests - selecting and specifying a worthy goal, and identifying a suitable policy measure to promote it - and given the latter's superior ability to assess them, it is important that policy analysis is adequately carried out. Appropriate policy analysis, as we shall demonstrate below, offers a method in which the proportionality tests can receive a more thorough and comprehensive handling than courts can usually offer. Better acquainting judges with policy analysis may assist and guide them in the process of judicial review. Such an approach infuses practical content into the distinction between the role of judicial review - which is limited to the evaluation of decisions - and the role of policy-making.

Understanding that a policy may involve infringement of rights, combined with awareness of the fundamental differences between policy analysis and judicial review, calls for better integration of the proportionality process in policy analysis. Relying on existing practices of policy analysis to implement the principle of proportionality can give policy analysts a greater role in protecting rights. Furthermore, a better understanding of policy analysis by judges may im- 
prove the way in which judicial review is conducted and may potentially diminish the tension between the branches of government.

\section{Proportionality and policy analysis}

In view of the differences discussed above between policy analysis and judicial review, this section presents a plausible, prescriptive method for integrating proportionality into policy analysis in order to improve the protection of rights in the policy process.

\section{The worthy goal test}

This test require that the goal be worthy, and different legal systems offer minimalist and expansive approaches to this requirement. The worthiness of a policy goal is primarily dependant on the factual question as to whether it is indeed publicly important. As noted above, a key preliminary stage in well-conducted policy analysis is to establish and specify the undesirable phenomenon that the policy is intended to mitigate. This professional standard forms the basis for prioritizing policy problems and the limited resources available for addressing them. In a similar vein, a clear specification of the undesirable phenomenon also serves the purpose of the worthy goal test, as an important first step in weighing the normative costs of policy, such as infringements of rights.

\section{Rights infringements}

While policy analysts are accustomed to considering policy goals, they are much less experienced in evaluating rights infringements which are often less transparent and harder to detect. It is important for policy analysts to understand and routinely evaluate potential rights infringements. In this regard they should appreciate both the individual and the societal implications of such infringements. For example, it is impossible to assess fully the social cost of a restriction on the freedom of political speech without understanding the essential role of political speech in the functioning of a democracy, as well as the chilling effects of such infringements beyond the direct ones. Such considerations can be addressed by legal advisors in the policy process and it is thus advisable to seek their input from the early stages of the analysis.

Policy analysts should primarily assess whether they are capable of addressing the problem effectively without infringing on any right. This point of departure stresses the professional importance of generating alternatives. A well-conducted policy analysis cannot rely on evaluation of a single alternative. When an alternative involves an infringement of rights, a normative reason to consider additional alternatives is added to the professional reasons. The constitutional obligation to protect certain rights requires that policy analysts exert creative effort in identifying alternatives for addressing the policy problem. These alternatives should vary in their levels of rights infringement.

As explained above, policy analysis is a much more flexible procedure than legal proportionality analysis and allows policy analysts to formulate alternatives that entail a lesser infringement of rights, or to revise existing alternatives in order to minimize their restriction of rights (narrow tailoring). However, in order to simplify the identification of the impact of potential alternatives on rights, it is recommended that a list of categorically unacceptable policy measures be drawn up. The core of such a list may include violations of pertinent international norms. ${ }^{5}$ To this, one may add measures that the policy analysts and their legal advisors deem

5 - Some examples are: torture; cruel, inhuman and degrading treatment; arbitrary killing; collective punishment; hostage-taking; medical experiments without consent; and violations of basic due process requirements (such as being tried in front of an impartial tribunal or being informed of the evidence against oneself). 
to be cruel, inhumane or degrading. Although the content of such a list may be contested, we think that it is important and useful to make a collective effort to create one in government agencies (where the constitution or legislation does not provide one).

The comparative evaluation of alternatives - an integral part of policy analysis - must address the potential for rights infringements. This practice is required as part of the state's duty to respect constitutionally protected rights. ${ }^{6}$ We suggest that, in practice, this duty requires inclusion of a rights-impact criterion in the evaluation process. Such a criterion should address the potential of the alternative to restrict, protect or promote rights. Including such a criterion may be an effective means of preventing rights infringements due to unawareness, since policy analysts would have to weigh the impact on rights of the alternative being considered, and explicitly state their conclusions in the comparative evaluation of the alternatives (see: Nelson et al., 1997). This key step of integrating a rights-impact assessment in policy analysis requires policy analysts, aided by legal advisors, to evaluate the potential effect of policy alternatives on rights and assign the appropriate weight to this criterion, which would then be factored into the comparative assessment of the alternatives. The rights-impact criterion utilizes the process of alternatives evaluation in order to integrate normative considerations, which are the key goal of courts in reviewing policy, within policy analysis.

A key difference between proportionality analysis conducted by courts and the consideration of rights in policy analysis is that the former tends to focus on one particular public goal, while policy analysis jointly weighs alternatives that promote more than one public goal and/ or potentially infringe on more than one right. In this process, policy analysis should compare infringements of rights by different alternatives, while also assessing the various options for minimising the policy problem and the undesirable phenomenon.

How should policy analysts weigh an infringement of a right against the benefits of a policy alternative? In such instances, legal advisors can make a professional contribution by advising them as to the relative weight and degree of harm of an infringement. In making these determinations, one may consider two options: a categorical ban on alternatives that infringe rights (especially when other feasible alternatives do not) or a very restrictive approach. In the case of the latter, a rights-infringing alternative can be permitted only if it is highly effective in promoting a highly important policy goal, with a high level of certainty (Alexy, 2010).

\section{The suitability test}

Unlike the courts' application of the suitability test as a threshold assessment, policy analysis is better at conducting an extensive examination of suitability. A recent comparative study suggests that apex courts in Germany, Israel, Poland, and Canada typically adopt a deferential approach, as they 'sum up the suitability stage in one or two sentences by finding that a measure is suitable or rationally connected to the goal, without further analysis. Furthermore, many courts seem not to insist on evidence to support the claim that the policy can effectively promote the goal, instead accepting statements made by policy-makers' (Steiner et al., 2020, p. 568).

Conversely, effectiveness assessment is a pivotal feature of policy analysis. A central criterion in the evaluation of policy alternatives is effectiveness, measured by the degree to which the undesirable phenomenon is expected to be mitigated by implementing the assessed policy alternative, and the level of certainty (or probability) of this effect. The expected mitigation by

6 - It is required, for example, by: the U.S. Constitution, Amendments I-X; the preamble to the French Constitution; Article 1 GG of the German Constitution; and Chapter 2 of the South African Constitution. 
implementing the policy represents its expected positive effect on the policy goal - which constitutes the suitability test. Effectiveness estimates regarding the various alternatives must be based on the best available evidence, including: past experience in the relevant country and in others; scientific research; and further conventional methods of assessment. Such a practice offers a sound basis for policy analysis and alleviates tendencies, especially among those proposing a particular policy, to over-estimate the potential of the policy by exaggerating its effectiveness or its probability of success, as well as the tendency to follow 'fashionable' but unsubstantiated solutions. Careful effectiveness estimates also facilitate communication of the process to parties who were not involved in the actual policy analysis - a particularly crucial aspect in the case of important public policies, including those that affect constitutional rights.

\section{The necessity test}

There are two main legal interpretations of the necessity test. According to the first, a policy fails this test if a less restrictive alternative is available - provided that this alternative is equally effective in promoting the policy goal (Barak, 2012, p. 323-324). The second interpretation places the emphasis on whether a less restrictive alternative exists, even if the latter is not equally effective (see: R. vs. Big M Drug Mart Ltd. 1985; R. vs. Oakes 1986). While the latter interpretation leaves some ambiguity as to the required similarity of effectiveness, the former appears to be intended to prevent only Pareto-inefficient alternatives. ${ }^{7}$ Even if one endorses the interpretation of the necessity test as requiring the least restrictive mean to be equally effective, it is clearly not appropriate for this approach to be followed in policy analysis by institutions that respect rights. First, this interpretation implicitly assumes that policy-makers are not obliged to give any weight to the protection of rights. Second, well performed policy analysis is more comprehensive than is proportionality analysis.

Given that proportionality analysis was intended for courts rather than policy analysts, it utilized four separate distinct evaluations, rather than a comprehensive analysis. Specifically, when courts evaluate compliance to the necessity test, they restrict their scrutiny to the comparison of effectiveness and rights infringement across alternatives; but when they implement the balancing test, they compare effectiveness and rights infringement within the chosen alternative. However comprehensive assessment of alternatives - which is an integral part of policy analysis - involves trade-offs between the different criteria across alternatives. When such analysis involves a criterion of rights impact, it practically incorporates both necessity and balancing. Under such circumstances, as noted earlier, requiring policy-makers to opt for an equally effective alternative that is less restrictive of rights is a minimalistic requirement, since no cost difference (in the currency of effectiveness) offsets the infringement of rights; thus it implicitly requires no more than zero weight for rights. In practice, such a requirement addresses a case in which the policy analyst failed to identify the infringement of a right entailed by the policy, and/or failed to detect an equally effective and less restrictive alternative, and these failures were detected in the course of the judicial review. However, when policy analysts are aware of such an alternative in the course of the policy analysis, they are obviously required to opt for it, since - as public agents - they are expected to give appropriate weight to the impact on rights as part of their duty to respect constitutional rights. Such circumstances, in fact, describe a situation of a dominant alternative (Colman, 2015, p. 219): the alternative is equal in all ways but one to a competing alternative, while being superior in that one criterion - rights impact - and thus must be chosen. Assigning a non-negligible weight to rights

7 - Moreover, the set of alternatives that satisfy the requirement of strictly equal effectiveness may be exceedingly small. 
therefore requires that policy analysts prefer less restrictive alternatives, even the cost of some effectiveness.

Assigning a non-negligible weight to rights in policy analysis requires a more flexible application of the necessity test. Selecting between alternatives based on a set of criteria that includes rights impact means that the policy plan that is not the best in terms of effectiveness, but which offers the best weighted average score across the set of criteria, should be selected. ${ }^{8}$

Our discussion of the implications of the necessity test for policy analysis so far can be summarized as making a case against adoption of its strict judicial version (which requires the least restrictive mean to be equally effective). However, we maintain that the essence of this test implies a positive conclusion: namely, the enhanced duty actively to seek alternatives that minimize rights infringement, and/or engage in narrow tailoring (revising and adapting the chosen alternative) in order to do so. Policy analysis based on a single alternative is generally undesirable for reasons of policy quality and is more susceptible to opportunity cost neglect (Persson \& Tinghog, 2020; Cohen-Blankshtain \& Sulitzeanu-Keenan, 2021). This is particularly true when the policy may impact on protected rights; in such a case, a normative disadvantage is added, since the single alternative is evaluated against the status quo only (i.e., the undesirable phenomenon). Under such conditions the likelihood of adopting the policy is high given the dominance of the policy goal, and the consequent restriction of rights is more likely to be perceived as an unavoidable side-effect (Steiner et al., Forthcoming). Developing several real alternatives which address both the policy problem and the undesirable phenomenon to appropriate degrees facilitates a more significant assessment of considerations that might otherwise be assigned lesser priority, such as the protection of rights.

A particular policy analysis that is related to the necessity test is narrow tailoring - the careful consideration and adaptation of alternatives so as to minimize the likelihood and extent of rights infringements. This may include assessing whether a policy is too broad, whether it is sensitive to diverse populations and circumstances, and whether it overly burdens certain disadvantaged social groups. For example, in 2000, the South African Supreme Court found that the government's failure to issue guidelines for the exercise of a regulatory discretion to allow spouses of permanent residents to remain in South Africa while applying for residence status amounted to an unjustifiable limitation of the right to dignity. The court accepted that controlling immigration is a legitimate policy objective and that the challenged limitation was rationally connected to that objective. However, issuing guidelines as to when and how discretion should be exercised would have been a less restrictive means of achieving that objective; thus the absence of such guidelines provided no guarantee that the discretionary powers would be exercised in a way that is congruent with constitutional values (Stacey, 2020, p. 276).

Policy analysts should consider whether those whose rights are affected by the policy can be expected to understand the policy even if they do not accept it, and to perceive it as a fair arrangement, or at least not see it as unjust. In other words, policy analysts should figure out whether promoting the policy goal by means of the chosen policy would benefit society in such a way that its individual members, including those whose rights are infringed, would be able

8 - It should be noted that a similar approach to the necessity test can be found in Canadian constitutional law, in the sense that it seeks to balance the harm of a rights infringement and the effectiveness of promoting the policy goal. See, for example: RJR-MacDonald Inc. v. Canada (Attorney General) S.C.R. 3199 (1995); Canada (Attorney General) v. JTI-Macdonald Corp., S.C.C. 30, S.C.R.2 610 (2007), which determined that, although an absolute ban on advertising tobacco products is more effective than a partial ban, the former should not be implemented given the balance between its marginal utility and the marginal harm to rights. 
to appreciate this. Lastly, in cases of substantial infringements of important rights of stable minority groups, we recommend that the policy-making process include direct consultations or hearings with representatives of these groups.

\section{The balancing test}

As noted above, the balancing test requires us to compare the marginal advancement of a worthy goal against the marginal restriction of rights (Barak, 2012). The former pertains to the effectiveness of an alternative, defined as the expected contribution of the policy to minimizing the undesirable phenomenon (multiplying the effect by its probability). This concrete benefit is the value that should be weighed against the expected impact on rights within the balancing test.

For example, the goal of an electronic surveillance measure intended to detect security threats (e.g., by scanning the content of emails) is, in general, national security. However, in order to determine whether the expected infringement of rights (in this case, privacy) is justified, we must assess the expected effectiveness of this policy measure. Specifically, we should estimate the change in the likelihood of preventing attacks and the expected benefits it may bring about (in human lives, etc.). Very few policy measures achieve complete elimination of an undesirable phenomenon; ${ }^{9}$ instead of abstract goals and marketing slogans, a thorough policy analysis may provide realistic estimates of the expected contribution of the policy to the goal.

Our suggestion to require policy analysts to include a rights-impact criterion in conducting alternatives evaluation would lead them to assess the expected effect on rights. The combination of evidence-based estimates of effectiveness and of the impact on rights, for each policy alternative, offers a robust method for applying the balancing test in policy analysis.

\section{Implications for judicial review}

Consistent with the integrative approach of this article, the following section identifies key implications of the proposed implementation of the proportionality principle in policy analysis for the practice of courts in conducting judicial review of policy.

The relative weakness of courts in implementing the worthy goal and the suitability tests (Stone-Sweet \& Mathews 2019, p. 138) lies in the fact that they typically defer to the position of the executive branch or legislature as to the importance and effectiveness of policies (see: Steiner et al., 2020, p. 562-563). Judicial deference varies depending on the characteristic of the dispute, the gravity of the issue and its level of technicality (Radaelli \& Taffoni, 2020). Indeed, the worthy goal test pertains to the political legitimacy of the legislature to determine policy goals, and the suitability test alludes to technical aspects of policy effectiveness; thus courts are less likely to challenge the substance of such legislative and executive assertions. However, the integration of proportionality in policy analysis produces observable outputs that provide procedural criteria for judicial review. Such criteria, as detailed below, offer new options for judges to review the policy processes that impinge on rights, while respecting the political and technical discretion of policy-makers.

Well-conducted policy analysis must establish the existence and magnitude of the undesirable phenomenon in a much more thorough manner. This professional standard, along with the normative burden on the state to justify rights infringements (as stated in the constitutions of most democracies), entails that when assessing the worthiness of a policy in the context

9 - Notable exceptions are some cases of public immunization, which practically eradicated several illnesses in countries that implemented them. 
of judicial review, courts should require policy-makers to present the factual evidence for the existence and magnitude of the undesirable phenomenon. ${ }^{10}$ In the absence of factual evidence, a stated goal may be deemed worthy yet superfluous, and thus cannot justify rights infringements. This understanding conforms to the opinion of the Canadian Supreme Court in R. $v$ Oakes (1986), according to which the policy goal should be linked to a 'pressing and substantial' public matter becoming a democratic society. The provision of such factual evidence gives substance to the application of the worthy goal prong in judicial review, while respecting the notion of separation of powers. It is the executive or legislative branch which provides the factual basis, while the courts focus on verifying that it has been provided.

While courts typically apply the suitability test as a threshold assessment, policy analysis provides a much more extensive examination by forming effectiveness estimates. In order to provide policy-makers with an incentive to conduct this analysis thoroughly, and to leverage it to inform the process of judicial review, we propose that judges who conduct proportionality analysis in judicial review require policy-makers to present detailed information on the suitability of the policy in question (see also: Roach, 2015, p. 416). Specifying the required evidence that should be presented in judicial review, in this way, is expected to reduce the likelihood of presenting an unsubstantiated policy position regarding the suitability tests, as exemplified by the Sauve No. 2 (2002) decision of the Canadian Constitutional Court (Stone-Sweet \& Mathews, 2019, p. 139-140). Failure to present such established estimates may act against the policy-maker, as the court may conclude that the stated policy goal is not the true purpose of the policy being assessed (Roach, 2015, p. 417).

As noted above, assessing multiple alternatives by policy analysts is not only a useful policyanalysis practice, but also facilitates the application of the necessity test. This point is accentuated by the relative disadvantage of courts in generating and assessing alternatives, and their dependence on identifying one or more available alternatives that policy-makers could have chosen (Stone-Sweet \& Mathews, 2019, p. 140-141). We therefore suggest that judges incentivize policy-makers to do so. Courts can do this by emphasizing the merit of alternatives evaluation in their judicial review. Instead of merely asking the parties whether a less restrictive means is possible, judges can ask policy-makers to present the alternatives considered in the policy-making process. Anticipating such a requirement in the judicial review would motivate policy-makers to seek additional policy alternatives ex ante - thus achieving the goal of the necessity test. Second, courts may rely on this as a procedural test in the judicial review, thus being able to engage more with the quality of the policy-making procedure rather than the policy substance, while reserving the option to delve into the latter in extreme cases.

Lastly, in addition to requiring policy-makers to present the estimated effectiveness of the policy in question to inform the suitability test, courts conducting judicial review may also require assessments of the expected effect on rights. Such requirements allow the court to assess whether the relevant authority can support the claim that the infringement of a right is justified, and constitute tasks that form an integral part of judicious policy analysis anyway. Adequate policy analysis requires that estimates regarding the effectiveness of a policy be based on factual evidence, not only for the purpose of proportionality analysis. Our suggestion to require policy analysts to include a rights-impact criterion in conducting alternatives evaluation would lead them to assess the expected effect on rights, and such an assessment could supplement the court's review in this regard.

10 - Some may argue that such a requirement unduly limits the prerogative of the executive and legislative branches to determine which goals are worthy. We join Roach (2015: 416) in arguing that this limitation applies only to policies that may infringe on constitutionally protected rights. 


\section{Discussion}

This article discusses the potential for integrating the proportionality principle in policy analysis, for enhancing the protection of rights in policy-making, and thus for improving the quality of policy. We acknowledge that these two bodies of knowledge are utilized by different officeholders in different professional sectors and fora. However, mutual understanding and appreciation across these domains may enhance the application of the principle of proportionality as a method of protecting rights, both by policy analysts and judges. Our aim is not to turn policy analysts into lawyers, nor to convert judges into policy analysts. Rather, we seek to increase mutual understanding, and especially to come up with practical suggestions that may address current limitations in the protection of rights by both policy analysts and judges. In the following, we present our conclusions and point out the limitations of our analysis, as well as the challenges that remain unanswered here.

Figure 1 depicts the relationships between the various stages of policy analysis and the different proportionality tests. These relationships are represented by the arrows, with each arrow's direction indicating the direction of influence, and each relationship labelled with a capital letter. Including a rights-impact criterion in a well-conducted policy analysis is consistent with the state's duty to respect constitutionally protected rights, and means that the three proportionality tests are likely to be addressed suitably to the best of the policy analysts' judgement. Requiring policy analysts to include this criterion $[\mathrm{B}]^{11}$ is expected to reduce the likelihood of restrictions on rights due to lack of awareness of the issue (Nelson et al., 1997). Furthermore, thorough policy analysis involves assessing the effectiveness of the various policy alternatives and creates the relevant information for implementing the necessity test. Incorporating the rights-impact criterion in the alternatives evaluation is a way of implementing the balancing test naturally. Lastly, the necessity test $[C]$ provides a normative justification, which coincides with the professional norm of evaluating multiple real alternatives and assessing the possibility of minimizing the restriction of rights by amending and adapting the alternatives under consideration.

We also find that a better understanding of policy analysis by judges has practical implications for the judicial review process. Since a well-conducted policy analysis is based on detailed factual inspection of the undesirable phenomenon, it makes perfect sense that this factual basis would serve as background for a judicial review of the worthiness of the goal [A]. Similarly, mere statements regarding the expected effectiveness of a chosen policy are not sufficient for the suitability test, and given that detailed effectiveness estimates are an integral part of policy analysis, they should inform any legal analysis of the suitability test [D]. Lastly, in its application of the balancing test, the court can consider the evidence presented by the policy-making body regarding the concrete goal (the marginal contribution of the policy to mitigating the undesirable phenomenon) and the expected impact of the policy on rights [E]. 
Figure 1: The relationship between policy analysis and proportionality analysis

Policy analysis $\quad$ Proportionality analysis

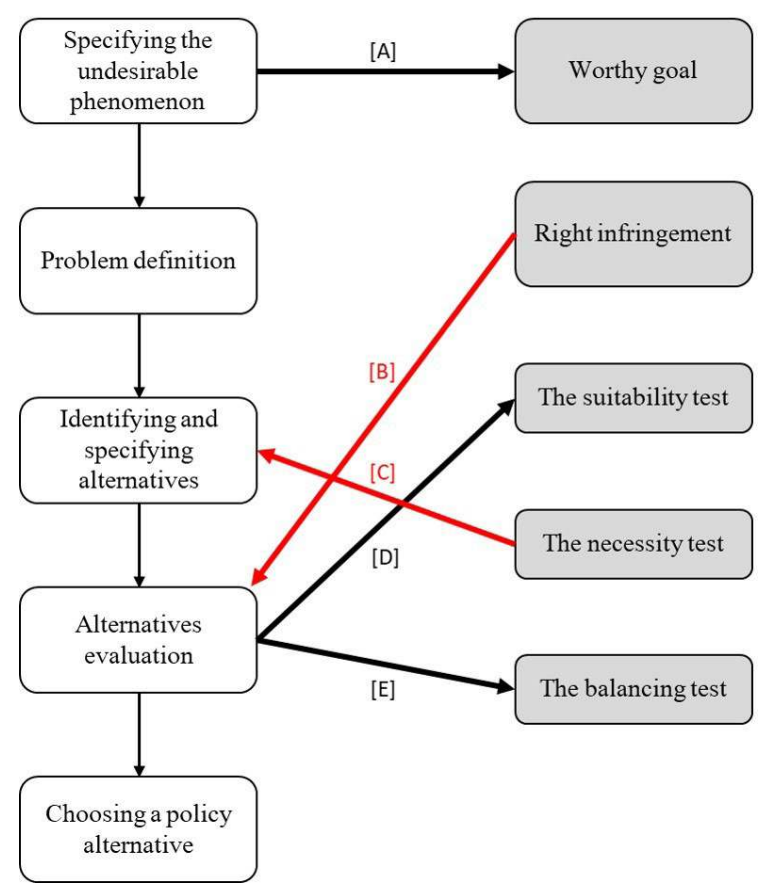

\section{Source: The Authors}

The proposed approach outlined in this article requires that the judiciary not merely settle the concrete disputes brought before it, but also guide policy analysts regarding the consideration of rights in the policy-making process. In line with the notion of deference, which shapes the division of powers between the judiciary and other branches of government (see: Dotan, 2020), such guidance can be substantive in areas where the judges have a relative advantage (e.g., articulating rights and stating their limits) and procedural with regard to rights considerations in the policy-making process itself. Thus the court can fulfil its duty to review the policy, rather than replacing the policy-makers' discretion with its own. Moreover, with this approach, the court can convey informative incentives for the promotion of rights considerations in the policy process, and fulfil its duty to seek to minimize infringement of rights.

The implications that we infer from the integrative analysis of the proportionality tests and the method of policy analysis rely on these generally accepted bodies of knowledge. In this respect, we take a conservative approach, in the sense that its novelty lies in integrating current professional norms of policy analysis with basic legal norms that exist in most constitutional democracies - particularly the duty of state institutions to respect the rights protected by the constitution. As far as judicial review is concerned, our approach is consistent with established views that emphasize procedural criteria in reviewing decisions of the executive and legislature (Bar-Siman-Tov, 2011; Coenen, 2002). One important advantage of this approach is that specific steps that can enhance the protection of rights are identified and can then immediately be implemented, without prerequisite reforms in the proportionality test or in established methods of policy analysis. Yet the limitations and shortcomings of our approach should also be noted so that critical readers can assess whether it is convincing on balance. 
A notable limitation concerns a characteristic of policy analysis which might be termed 'goal uniqueness'. Policy analysts are typically guided by the question of whether a policy is likely to be effective at minimizing the undesirable phenomenon. For policy analysts, restriction of rights amounts to an adverse side effect - and, in our view, a required criterion in alternatives evaluation. One may question, however, whether constitutional requirements that state institutions respect human and civil rights are consistent with a policy-making process in which rights are not a goal in their own right, but merely a criterion.

An alternative to this might identify rights as additional goals, beyond the specific policy goal. This does not mean making the promotion of rights a goal to be taken into account in all policy analyses, as many policies have no impact on rights; it applies only in those cases where they do have such an impact. This alternative approach can be justified in at least two ways. First, it reflects the constitutional requirement that public institutions respect rights, implying that restrictions of rights must be exceptions that require powerful justification. Second, it counterbalances the subservient status that rights may have in practice in the policy-making process. This status may stem from a tendency to perceive rights as the interest of individuals, unlike the public interest, which is typically associated with the public at large. ${ }^{12}$ Forming a clear and comprehensive understanding of the meaning and implications of restricting rights is extremely challenging. This challenge is exacerbated by the professional motivations of policy analysts, who are typically entrusted with promoting public interests.

Conversely, because the current practice of policy analysis does not require that protection of rights be a policy goal, requiring such a general policy goal is much more challenging and uncertain. Moreover, it is plausible that mandating a rights-impact criterion in policy analysis is sufficient for the protection of rights in most cases. Obviously, in cases where the policy goal is indeed the promotion of rights, there is no practical reason not to do it. This is the case for both negative rights, such as preventing discrimination, and positive rights, such as the right to education (Berlin, 1969; Currie, 1986). In such cases the infringement of the right constitutes the undesirable phenomenon, and the entire policy will be aimed at minimizing it. Note that, even in such cases, a rights-impact criterion should be required in order to assess potential restrictions of rights other than the one intended to be promoted by the policy.

To conclude, the present study points out the inherent potential of integrating the proportionality principle in policy analysis for enhancing the protection of rights in the policy process. First, mandating the inclusion of a rights-impact criterion in policy analysis is expected to increase the likelihood that the three proportionality tests will be addressed in the analysis. Second, the professional norm of considering several distinct alternatives satisfies the normative requirement of the necessity test and facilitates the mitigation of rights restrictions through the comparison and modification of the alternatives. Third, since professional policy analysis must rely on establishing a factual basis for the undesirable phenomenon, it stands to reason that this factual basis would be presented in the course of judicial review of the policy goal and the three proportionality tests. Adopting these practical measures may substantially assist the court in identifying ways to implement its judicial review, while respecting the discretion of the executive branch and/or legislature. Finally, these proposed practices are expected to streamline the incentive structure of policy-makers for conducting quality policy analysis while protecting human and civil rights.

12 - When the right in question is that of an 'other' - not a member of the majority group - its weight suffers even more. 


\section{Bibliography}

Alexy, R. (2010). A Theory of Constitutional Rights. New York, NY: Oxford University Press.

Arnott, R., Rave, T., \& Schöb, R. (2005). Alleviating Urban Traffic Congestion. Cambridge, MA: MIT Press.

Bar-Siman-Tov, I. (2011). The puzzling resistance to judicial review of the legislative process. Boston University Law Review, 91, 1915-1974.

Barak, A. (2012). Proportionality: Constitutional Rights and Their Limitations. Cambridge: Cambridge University Press.

Bardach, E., \& Patashnik, E. M. (2019). A Practical Guide for Policy Analysis: The Eightfold Path to More Effective Problem Solving. Thousand Oaks, CA: CQ Press Sage.

Beatty, D. M. (2004). The Ultimate Rule of Law. Oxford: Oxford University Press.

Berlin, I. (1969). Two concepts of liberty. In I. Berlin (Ed.), Four Essays on Liberty (pp.118-172). Oxford: Oxford University Press.

Coenen, D. T. (2002). The Rehnquist court, structural due process, and semisubstantive constitutional review. Southern California Law Review, 75, 1281-1405.

Cohen, S. (2011). Folk Devils and Moral Panics. London: Routledge.

Cohen-Eliya, M., \& Porat, I. (2013). Proportionality and Constitutional Culture. Cambridge: Cambridge University Press.

Cohen-Blankshtain, G., \& Sulitzeanu-Kenan, R. (Forthcoming). Foregone and Predicted Futures: Challenges of opportunity cost neglect and impact bias for public participation in policymaking. Journal of European Journal of Public Policy.

https://doi.org/10.1080/13501763.2021.1912152

Colman, A. M. (2015). A Dictionary of Psychology (4th Ed.). Oxford: Oxford University Press.

Currie, D. P. (1986). Positive and negative constitutional rights. University of Chicago Law Review, 53(3), 864-890.

Dawood \& Another v Minister of Home Affairs \& Others; Shalabi \& Another v Minister of Home Affairs \& Others; Thomas \& Another v Minister of Home Affairs \& Others , 2000 (3) SA 936 (CC) (SA)

Dery, D. (1984). Problem Definition in Policy Analysis. Lawrence, KS: University of Kansas Press.

Dery, D. (2000). Agenda setting and problem definition. Policy Studies, 21(1), 37-47.

Dotan, Y. (2020). Two concepts of deference. Administrative Law Review, 71(4).

Eitan Israel Migration Policy v Government of Israel 2014, HCJ 7385/13 (IL) (22 September 2014).

Felstiner, W. L. F., Abel, R. L., \& Sarat, A. (1980). The emergence and transformation of disputes: Naming, blaming, claiming.... Law \& Society Review, 15(3), :631-654.

Fisher, L. (1988). Constitutional Dialogues: Interpretation as Political Process. Princeton, NJ: Princeton University Press.

Goode, E., \& Ben-Yehuda, N. (2009). Moral Panics: The Social Construction of Deviance. Chichester: Wiley-Blackwell. 
Haas, P. M. (1992). Introduction: epistemic communities and international policy coordination. International organization, 46(1), 1-35.

Hammond, J. S., Keeney, R. L., \& Raiffa, H. (2015). Smart Choices: A Practical Guide to Making Better Decisions. Boston, MA: Harvard Business School Press.

Henderson, V. J. (1981). The economics of staggered work hours. Journal of Urban Economics, 9(3), 349-364.

Hiebert, J. (2006). Parliamentary Bills of Rights: An Alternative Model?. Modern Law Review, 69, 7-28.

Hirschfeld Davis, J., \& Shear, M.D. (2018, June 15). How Trump came to enforce a practice of separating migrant families. The New York Times.

Hogg, P., \& Bushell, A. (1997). The Charter Dialogue Between Courts and Legislatures (Or Perhaps the Charter of Rights Isn't Such a Bad Thing After All). Osgoode Hall Law Journal, 35, 75--124.

Hurka, T. (2005). Proportionality in the morality of war. Philosophy \& Public Affairs, 33(1), 34-66.

Jackson, V. (2004). Being proportional about proportionality. Constitutional Commentary, 21, 80359.

Kumm, M. (2007). Political liberalism and the structure of rights: On the place and limits of the proportionality requirement. In P. George (Ed.), Rights and Discourse: Themes from the Legal Philosophy of Robert Alexy (pp. 131-165). Portland, OR: Hart Publishing.

Kumm, M. (2010). The idea of Socratic contestation and the right to justification: The point of rights-based proportionality review. Law Ethics of Human Rights, 4(2), 141-175.

Motsenok, M., Steiner, T. Steiner, Netzer, L. Netzer, Feldman, Y., \& Sulitzeanu-Kenan, R. (2020). The Slippery Slope of Rights-Restricting Temporary Measures: an Experimental Analysis. Behavioural Public Policy, 1-21.

Nelson, T. E., Clawson, R. A., \& Oxley, Z. M. (1997). Media framing of a civil liberties conflict and its effect on tolerance. American Political Science Review, 91(3), 567-583.

OECD (2017). Data: Road accidents. Retrieved from: 14 March 2019. https://data.oecd.org/transport/road-accidents.htm.

Persson, E., \& Tinghög, T. (2020). Opportunity cost neglect in public policy. Journal of Economic Behavior and Organization, 170, 301-312.

Petersen, N. (2013). How to compare the length of lines to the weight of stones: Balancing and the resolution of value conflicts in constitutional law. German Law Journal, 14, 1387.

Petersen, N. (2014a). The German constitutional court and legislative capture. International Journal of Constitutional Law, 12(3), 650-669.

Petersen, N. (2014b). Proportionality and the incommensurability challenge: Some lessons from the South African constitutional court. South African Journal of Human Rights, 30(3), 405-429.

Radaelli, C. M., \& Taffoni, G. (2020). The Trustworthiness Test for Regulatory Impact Assessment and Judicial Review. In M. De Benedetto, N. Lupo \& N. Rangone (Eds.), The Crisis of Confidence in Legislation (pp. 101-120). London: Hart Publishing.

Reich, R. B. (1988). The Power of Public Ideas. Cambridge, MA: Harvard University Press. 
Roach, K. (2015). The varied roles of courts and legislatures in rights protection. In M. Hunt, H. Hooper \& P. Yowell (Eds.). Parliaments and Human Rights: Redressing the Democratic Deficit, (pp. 405421). London: Hart Publishing.

R. v. Big M Drug Mart Ltd (1985). S.C.R. 295. (CA).

R. v. Oakes (1986). R.C.S. 103. (CA).

Scherer, M., \& Dawsey, J. (2018, June 16). Trump cites as a negotiating tool his policy of separating immigrant children from their parents. The Washington Post.

Stacey, R. (2020). Proportionality Analysis by the South African Constitutional Court. In M. Kremnitzer, T. Steiner, \& A. Lang (Eds.), Proportionality in Action: Comparative and Empirical Perspectives on the Judicial Practice (pp. 193-284). Cambridge: Cambridge University Press.

Steiner, T. (2020) Proportionality Analysis by the Israeli Supreme Court. In M. Kremnitzer, T. Steiner, \& A. Lang (Eds.), Proportionality in Action: Comparative and Empirical Perspectives on the Judicial Practice (pp. 285-384). Cambridge: Cambridge University Press.

Steiner, T. Lang, A. \& Kremnitzer, M. (2020). Comparative and Empirical Insights into Judicial Practice: Towards an Integrative Model of Proportionality. In M. Kremnitzer, T. Steiner, \& A. Lang (Eds.), Proportionality in Action: Comparative and Empirical Perspectives on the Judicial Practice (pp. 542-611). Cambridge: Cambridge University Press.

Steiner, T. Netzer, L., \& Sulitzeanu-Kenan, R. (Forthcoming). Necessity or Balancing: The Protection of Rights under Different Proportionality Tests - Experimental Evidence. International Journal of Constitutional Law.

Stone Sweet, A. (2000). Governing with Judges: Constitutional Politics in Europe. Oxford: Oxford University Press.

Stone Sweet, A., \& Mathews, J. (2008). Proportionality balancing and global constitutionalism. Columbia Journal of Transnational Law, 47, 72.

Stone Sweet, A. \& Mathews, J. (2019). Proportionality balancing \& Constitutional Governance: A Comparative \& Global Approach. Oxford: Oxford University Press.

Sulitzeanu-Kenan, R., Kremnitzer, M., \& Alon, S. (2016). Facts, preferences, and doctrine: An empirical analysis of proportionality judgment. Law \& Society Review, 50(2), 348-382.

Weimer, D. I., \& Vining, A. R. (2010). Policy Analysis: Concepts and Practice. Boston, MA: Routledge. World Health Organization (2015). Global status report on road safety 2015. 